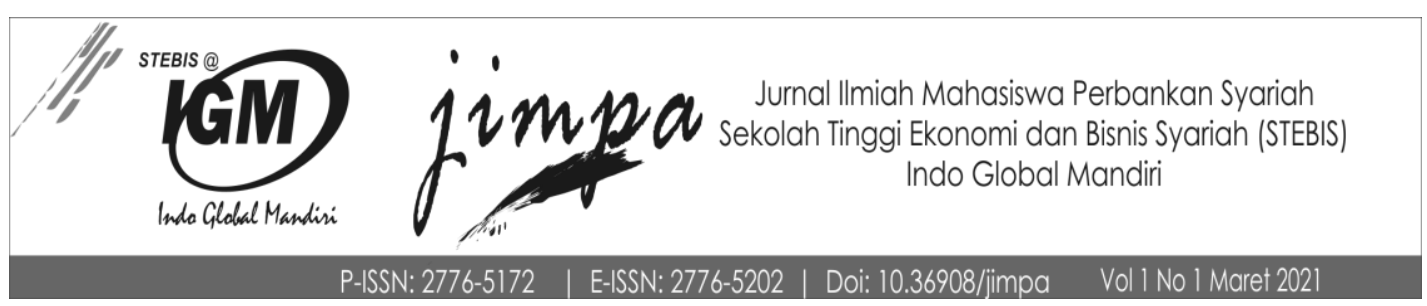

\title{
Etos Kerja Stebis Igm Di Sekolah Tinggi Ekonomi Dan Bisnis Syariah Indo Global Mandiri Palembang
}

\author{
Ulpa Dwiyanti ${ }^{1}$, Meriyati $^{2}$ \\ ${ }^{1}$ Mahasiswa Perbankan Syariah STEBIS IGM \\ ${ }^{2}$ Sekolah Tinggi Ekonomi dan Bisnis Syariah (STEBIS) Indo Global Mandiri \\ Email: Ulpadwy18@gmail.com, meri@stebisigm.ac.id
}

\begin{abstract}
Abstrak
Work ethic is said to be a determining factor for the success of individuals, groups, institutions and also the widest part of the nation in achieving its goals. The implementation of public administration is also influenced by the work ethic possessed by public officials in carrying out the needs of society. Work ethic is the main thing in carrying out work to achieve excellence in character and excellence of character that results in superior work and performance. Of course, these advantages come from the fruit of a human's perseverance. The ability to live work is very important in an effort to create excellence. The point is that when we do a job, we are essentially doing a service process. Living up to work as a service requires transcendent abilities that go beyond the small human space. This can all be seen and contained in the work ethic at the Indo Global Mandiri School of Sharia Economics and Business, Palembang.
\end{abstract}

Keywords: Work ethic, service process

\begin{abstract}
Abstrak
Etos kerja dikatakan sebagai faktor penentu dari keberhasilan individu, kelompok, institusi dan juga yang terluas ialah bangsa dalam mencapai tujuannya.Pada pelaksanaan administrasi publik juga dipengaruhi oleh etos kerja yang dimiliki oleh pejabat-pejabat publik dalam tugasnya menyelenggarakan kebutuhan masyarakat. Etos kerja merupakan hal yang utama dalam melaksanakan pekerjaan untuk mencapai keunggulan budi dan keunggulan karakter yang menghasilkan kerja dan kinerja yangunggul pula.Tentunya, keunggulan tersebut berasal dari buah ketekunan seorang manusia.Kemampuan menghayati pekerjaan menjadi sangat penting sebagai upaya menciptakan keunggulan. Intinya, bahwa saat kita melakukan suatu pekerjaan maka hakikatnya kita sedang melakukan suatu proses pelayanan. Menghayati pekerjaan sebagai pelayanan memerlukan kemampuan transendensi yang bersifat melampaui ruang gerak manusia yang kecil. Hal ini semua dapat terlihat dan tertuang dalam etos kerja di Sekolah Tinggi Ekonomi
\end{abstract}


Dan Bisnis Syariah Indo Global Mandiri Palembang

Kata Kunci: Etos Kerja, Proses Pelayanan.

\section{Pendahuluan}

Etos kerja Islam pada perbankan syariah merupakan bagian dari konsep Islam yang merupakan nilai-nilai untuk membentuk keperibadian dalam bekerja. Program pelatihan etos kerja ini adalah tentang penginternalisasian dan pencerahan nilai-nilai budaya kerja suatu lembaga instansi, agar para karyawan lembaga instansi mampu menyatukan pikiran dan perasaannya untuk berjuang dan bekerja keras bersama nilai-nilai budaya kerja yang dimiliki oleh lembaga instansi tersebut. Dan pelatihan etos kerja ini bertujuan untuk memenuhi standar perilaku kerja yang mengikuti budaya kerja lembaga instansi, serta membangun etika kerja yang kuat, agar kariyawan lembaga instansi mampu mengembangkan kepribadiannya bersama etos kerja lembaga instansi di tempat mereka bekerja untuk masa depan yang cemerlang. Program ini meletakkan dasar untuk pembelajaran keterampilan etos kerja dan keterampilan untuk meningkatkan kualitas diri.

Pada dasarnya wujud nyata suatu kerja lapangan tersebut ialah untuk mendidik mahasiswa agar mampu menerapkan ilmu yang didapat di bangku kuliah kedalam dunia industri dan bisnis. Namun kenyataannya yang terjadi pada wujud dari magang ini hanya sekedar "formalitas" yaitu untuk memenuhi suatu perintah dari instansi terkait sebagai syarat pelaksaaan magang. Akan tetapi magang tersebut adalah bentuk nyata dari hasil belajar yang di dapat di bangku perkuliahan. Oleh karena itu apabila budaya kerja dan etos kerja islam berjalan dengan baik maka kinerja karyawan akan ikut lebih baik (meningkat).

\section{Landasan Teori}

\section{Sejarah STEBIS IGM}

Yayasan Indo Global Mandiri (IGM) didirikan pada tanggal 5 Oktober 1998 bertepatan dengan hari ulang tahun Tentara Nasional Indonesia (TNI) dengan akte Notaris Janti Gunardi, S.H. Pendirian Yayasan IGM diprakarsai oleh para Profesional yang berpengalaman sangat luas dalam bidang kependidikan, pengembangan sistem informasi dan komputer yang berbasis Teknologi Informasi serta mempunyai komitmen yang sangat besar untuk meningkatkan kualitas SDM Indonesia dalam rangka mengantisipasi persaingan global.

Sebagai bentuk kepedulian kepada masyarakat yang belum beruntung, Yayasan IGM juga memberikan beasiswa kepada anak yatim / piatu dan 
atau kurang mampu berupa pendidikan Gratis yang dibina di Pondok Pesantren Modern IGM Al-Thsaniah untuk tingkat Tsanawiyah dan Aliyah.

Bentuk Kegiatan sosial lainnya yang dilaksanakan oleh Yayasan IGM, adalah memberikan bimbingan secara gratis kepada calon jemaah haji mulai di Indonesia sampai di Tanah suci, dengan mendirikan KBIH IGM-Al Ikhsaniyah pada tahun 2001, disamping memberikan bantuan kepada kelompok-kelompok masyarakat yang masih memerlukan bantuan baik dalam bentuk bakti sosial, bantuan dana maupun konsultasi pegembangan ekonomi kerakyatan. Pada Tahun 2014 diresmikan Sekolah Tinggi Ekonomi dan Bisnis Syariah dengan tujuan untuk memenuhi keinginan masyarakat Sumatera Selatan pada umumnya mengenai tata cara perekonomian syariah. Mudah-mudahan Yayasan IGM akan terus berkiprah memberikan kontribusi yang konkrit dan positif serta bermanfaat bagi kesejahteraan masyarakat.

Sekolah Tinggi Ekonomi dan Bisnis Syariah Indo Global Mandiri yang berdiri di bawah naungan Yayasan Indo Global Mandiri, Kemudian dikenal dengan singkatan STEBIS IGM, didukung beberapa faktor. Pertamaide pembangunan sekolah tinggi ini muncul dari para pendiri yayasan dan tumbuhnya lembaga-lembaga keuangan syariah seperti bank, asuransi, pegadaian, pembiayaan, dan lain-lain serta menguatnya kembali ekonomi Islam di dunia. Kedua, pertimbangan bahwa perguruan tinggi swasta berbasis syariah belum ada di Sumatera Selatan. Ketigapertumbuhan madrasah, pesantren dan perguruan agama sederajat dengan SLTA tumbuh berkembang, yang pada gilirannya memerlukan adanya lembaga pendidikan lebih tinggi. Disamping itu perkembangan zaman dan tuntutan masa memang memerlukan tenaga ahli yang professional - terampil dalam bidang perekonomian syariah.

STEBIS IGM memiliki dua program studi yaitu: Program Studi Ekonomi Syariah untuk jenjang S1 dan Perbankan Syariah untuk jenjang D3 yang terdaftar di Kopertais Wilayah VII Sumbagsel dengan izin penyelenggaraan yang diberikan oleh Dirjen Pendidikan Islam SK Nomor 2516 tahun 2014 tanggal 5 Mei 2014 tentang Persetujuan Pendirian Perguruan Tinggi Agama Islam Swasta. Sekolah Tinggi Ekonomi dan Bisnis Syariah (STEBIS) Indo Global Mandiri dibawah Direktorat Jenderal Pendidikan Islam Kementerian Agama RI dengan Nomor Statistik NSPTI: 143167107037 STEBIS IGM beralamat di Jl. Jend. Sudirman KM.4 No.629, 20 Ilir D. IV, Kec. Ilir Tim. I, Kota Palembang, Sumatera Selatan 30129.

\section{Visi dan Misi STEBIS IGM}

Visi, menjadi sekolah tinggi yang bermutu dan terkemuka dalam menghasilkan lulusan yang mampu mengintergrasikan nilai-nilai syari'ah 
untuk kemaslahatan umat pada tahun 2022. Sedangkan Misi, antara lain: a). menyelenggarakan pola pendidikan dan pengajaran perbankan syari'ah yang berkualitas, dalam rangka melahirkan sumber daya manusia yang unggul, mampu bersaing dalam skala global, mandiri dan berakhlak mulia, serta mampu mengimplementasikan nilai-nilai keislaman dalam bidang ekonomi secara benar dan jujur, b). Berperan serta dalam mendidik masyakat beriman, bertaqwa dan berkeadilan melalui impelementasi dan aktualisasi ekonomi syari'ah dan perbankan syari'ah, c). Menciptakan iklim kondusif demi teraksana TriDarma perguruan tinggi. (www.stebisigm.ac.id)

\section{Definisi Operasional Teori Etos Kerja}

Menurut Sugiyono (2012:31) definisi operasional adalah penentuan konstruk atau sifat yang akan dipelajari sehingga menjadi variabel yang dapat diukur, sebagai berikut: Disiplin kerja, adapun indikator disiplin kerja menurut sastro hadiwiryo (2013:291) yaitu: 1)Frekuensi kehadiran, 2). Tingkat kewaspadaan, 3). Ketaatan pada standar kerja, 4). Ketaatan pada peraturan kerja, 5). Etika kerja.

Motivasi kerja, Adapun indikator motivasi kerja menurut sastrohadiwiryo (2013:268) yaitu : a). Kinerja, b). Penghargaan, c). Tantangan dan tanggung jawab, d). Pengembangan, e). Keterlibatan dan kesempatan.

Etos kerja, adapun indikator etos kerja menurut sinamo (2005:151) yaitu : a). Penuh tanggung jawab, b). Semangat kerja yang tinggi, c). Berdisiplin, d). Tekun dan serius, e). Menjaga martabat dan kehormatan. Lingkungang kerja, adapun indikator lingkungan kerja menurut sadarmayanti (2009:46) yaitu: a). Penerangan, b). Suhu udara, c). Suara bising, d). Warna dan ruang gerak, e). Keamanan dan hubungan kariyawan. Produktivitas kerja, adapun indikator produktivitas kerja menurut simamora (2004:112) yaitu: a). Kuantitas kerja, b). Kualitas kerja, c). Ketepatan waktu penyelesaian suatu pekerjaan, d). Sikap kooperatif, meliputi sikap terhadap organisasi, pimpinan, karyawan lain dan kerja sama.(Jurnal Pengaruh Disiplin Kerja, hlm 35-36).

\section{Teori yang Mendukung}

Dari kata etos ini dikenal pula kata etika, etiket yang hampir mendekati pada pengertian akhlak atau nilai-nilai yang berkaitan dengan baik buruk (moral),sehingga dalam etos tersebut terkandung gairah atau semangat yang amat kuat untuk mengerjakan sesuatu secara optimal, lebih baik dan bahkan berupaya untuk mencapai kualitas kerja yang sesempurna mungkin. Sebagai suatu subjek dari arti etos tersebut adalah etika yang 
berkaitan dengan konsep yang dimiliki oleh individu maupun kelompok untuk menilai apakah tindakan-tindakan yang telah dikerjakan itu salah atau benar, buruk atau baik. (Tasmara, 2002).

Hadits Rasulullah SAW mengatakan: “Orang mu'min yang paling sempurna imannya adalah mereka yang paling baik akhlahnya." (HR.Turmudzi). Dalam bekerja seorang karyawan dituntut untuk bertutur kata yang sopan, bersikap bijak, makan dan minum sesuai dengan tuntunan Islam, berhadapan dengan orang lain dengan baik, rapat juga dengan sikap terpuji dan sebagaimana menunjukkan jati dirinya sebagai seorang yang beriman. Bahkan dalam hadits lain Rasulullah SAW menggambarkan bahwa terdapat dua sifat yang tidak mungkin terkumpul dalam diri seorang mu'min yaitu bakhil dan akhlak yang buruk (HR. Turmudzi). (http://rikzamaulana.blogspot.co.id/2009/01/)

Sebagai garis besar teori kerja pada perbankan syariah mempunyai beberapa faktor yang mendorong kinerja karyawan dilihat dari etos kerja, disiplin kerja, dan komitmen organisasi. Disiplin kerja dan komitmen organisasi sangat berpengaruh positif dan signifikan terhadap kinerja karyawan sebaliknya disiplin kerja dan komitmen organisasi berpengaruh terhadap kinerja karyawan. Manajemen perusahaan sebaiknya lebih memperhatikan etos karyawan agar hasil kerja karyawan lebih meningkat. Menurut henry simamora dalam mangkunegara (2007) kinerja di pengaruhi oleh tiga faktor, yaitu: a). Faktor individual yang terdiri dari: kemampuan dan keahlian, latar belakang dan demografi, b). Faktor psikologis yang terdiri dari: persepsi, attitude, personality, pembelajaran, dan motivasi, c). Faktor organisasi yang terdiri dari: sumber daya, kepemimpinan, penghargaan, struktur, dan job design. (https://doi.org/10.35794/emba.p3i2.9284).

Sedangkan menurut AnarogaEtos kerja dipengaruhi oleh beberapa faktor yaitu: Agama, pada dasarnya agama merupakan suatu sistem nilai yang akan mempengaruhi atau menentukan pola hidup para penganutnya. Cara berpikir, bersikap dan bertindak seseorang tentu diwarnai oleh ajaran agama yang dianut jika seseorang sungguh-sungguh dalam kehidupan beragama. Etos kerja yang rendah secara tdak langsung dipengaruhi oleh rendahnya kualitas keagamaan dan orientasi nilai budaya yang konservatif turut menambah kokohnya tingkat etos kerja yang rendah.

Budaya, sikap mental, tekad, disiplin, dan semangat kerja masyarakat juga disebut sebagai etos budaya dan secara operasional etos budaya ini juga disebut etos kerja. Kualitas etos kerja ini ditentukan oleh sistem orientasi nilai budaya masyarakat yang bersangkutan. Masyarakat yang memiliki sistem nilai budaya maju akan memiliki etos kerja yang tinggi dan sebaliknya. Masyarakat yang memiliki sistem nilai budaya yang konservatif 
akan memiliki etos kerja yang rendah, bahkan bisa sama sekali tidak memiliki etos kerja.

Sosial politik, tinggi rendahnya etos kerja suatu masyarakat dipengaruhi oleh ada atau tidaknya struktur politik yang mendorong masyarakat untuk bekerja keras dan dapat menikmati hasil kerja keras dengan penuh. Etos kerja harus dimulai dengan kesadaran akan pentingnya arti tanggung jawab kepada masa depan bangsa dan negara. Dorongan untuk mengatasi kemiskinan, kebodohan dan keterbelakangan hanya mungkin timbul jika masyarakat secara keseluruhan 30 memiliki orientasi kehidupan yang terpacu ke masa depan yang lebih baik.

Kondisi lingkungan, etos kerja dapat muncul dikarenakan faktor kondisi geografis. Lingkungan alam yang mendukung mempengaruhi manusia yang berada di dalamnya melakukan usaha untuk dapat mengelola dan mengambil manfaat, bahkan dapat mengundang pendatang untuk turut mencari penghidupan di lingkungan tersebut: Pendidikan, etos kerja tidak dapat dipisahkan dengan kualitas sumber daya manusia. Peningkatan sumber daya manusia akan membuat seseorang mempunyai etos kerja keras. Meningkatnya kualitas penduduk dapat tercapai apabila ada pendidikan yang merata dan bermutu disertai dengan peningkatan dan perluasan pendidikan, keahlian, dan keterampilan sehingga semakin meningkat pula aktivitas dan produktivitas masyarakat sebagai pelaku ekonomi

Struktur ekonomi, tinggi rendahnya etos kerja suatu masyarakat dipengaruhi oleh ada atau tidaknya struktur ekonomi, yang mampu memberikan intensif bagi anggota masyarakat untuk bekerja keras dan menikmati hasil kerja keras mereka dengan penuh. Motivasi intrinsik individu, individu yang akan memiliki etos bermotivasi tinggi. Etos kerja merupakan suatu pandangan dan sikap yang didasari oleh nilainilai yang diyakini seseorang. Keyakinan inilah yang menjadi suatu motivasi kerja. Maka etos kerja juga dipengaruhi oleh motivasi seseorang yang bukan bersumber dari luar diri, tetapi yang tertanam dalam diri sendiri yang sering disebut dengan motivasi intrinsik.

\section{Metode Penelitian}

Penelitian ini merupakan penelitian kualitatif. Data yang diperoleh dalam penelitian ini merupakan data primer karena berdasarkan wawancara langsung kepada staf dan karyawan yang ada di Sekolah Tinggi Ekonomi Dan Bisnis Syariah Indo Global Mandiri Palembang Hasil Dan Pembahasan

Analisis teori etos kerja bertujuan untuk memenuhi standar perilaku kerja yang mengikuti budaya kerja suatu lembaga. Adapun beberapa 
contoh etos kerja yang dapat kami bangun dan kembangkan demi kesuksesan karir, antara lain: a). Contoh etos kerja di perusahaan. Etos kerja sendiri disebut sebagai salah satu faktor yang di percaya dapat menunjang kesuksesan karir seseorang. Pasanya, banyak perusahaan mencari karyawan dengan etos kerja yang tinggi karena dinilai dapat berkontribusi maksimal pada pencapaian tujuan perusahaan, b). Disiplin, Disiplin adalah contoh etos kerja yang harus dimiliki dalam pekerjaan.

Kariyawan yang disiplin biasanya secara sadar akan berusaha sebaik mungkin untuk memenuhi dan bahkan meningkatkan kinerja mereka. Contohnya: 1). Tepat waktu masuk ruangan. 2). Mendapatkan izin pimpinan apabila ingin meninggalkan tempat kerja selama jam kerja. 3). Mengenakan seragam kerja dan perlengkapan. 4). Mengenakan tanda pengenal (name tag) pada saat bekerja. 5). Menjaga peralatan kerja dan lingkungan instansi.

Berintegritas, adalah seseorang dengan etos kerja yang tinggi akan menunjukkan integritas di tempat kerja. Contohnya: a). mentaati peraturan kampus, b). Menyampaikan sesuatu yang tidak bisa dilakukan dari awal, c). Memenuhi tanggung jawab yang diberikan kepada kita, d). Selalu meghormati saran dan pendapat orang lain, e). Harus bertindak transparan dan konsisten.

Memiliki Profesionalisme Kerja, profesionalisme kerja adalah contoh etos kerja lainnya yang harus kita miliki untuk mengembangkan karir. Contohnya : 1). berpakaian sesuai aturan kampus. 2). Menghargai rekan kerja tanpa pandang bulu. 3). Harus berfikir maju, kreatif untuk mengembangkan skill yang ada. 4). Menjadi karyawan yang berkompeten. 5). Tetap bersikap sopan dan santun terhadap pimpinan.

Dapat Diandalkan, adalah seseorang yang dapat di andalakan dan di percaya terutama dalam hal pekerjaan. Contohnya : 1. mengumpulkan tugas atau pekerjaan sesuai dengan jadwal yang di tentukan. 2). Mampu mengerjakan tugas yang diberikan walaupun tidak sesuai bidang. 3). Dapat memberikan solusi untuk permasalahan yang dihadapi. 4). Dapat menyumbangkan pikiran dan tenaga dalam suatu pekerjaan tim. 5). Selalu memegang komitmen.

Dedikasi Dalam Pekerjaan, Komitmen yang kuat adalah komitmen yang kuat secara konsisten dalam pekerjaan. contohnya : 1). Mereka menyelesaikan tugas dengan maksimal meskipun harus menyediakan waktu lebih untuk itu. 2). Selalu menghargai waktu yang ditunjukkan dengan sikap tepat waktu. 3). Tidak mudah putus asa dalam melakukan suatu pekerjaan. 4). Menghargai ide dan kinerja rekan kerja. 5). Selalu berusaha sebaik mungkin dalam mengerjakan tugas.

Mampu Bekerja Sama, Ialah mampu bekerja sama dalam tim dengan baik 
Contoh : 1. tugas kelompok magang, 2. menjaga komunikasi antar rekan kerja. 3). Saling memberikan suport satu sama lain. 4). Mengutamakan kepentingan bersama daripada kepentingan pribadi. 5). Menghargai pendirian rekan kerja dalam tim.

Bertanggung Jawab, Bertanggung jawab berarti mau mengakui kesalahan dan berusaha secara proaktif untuk memperbaikinya Contohnya : 1). Menyelesaikan tugas dengan baik dan tepat waktu. 2). Selalu bersikap konsisten dalam melakukan tugas. 3). Tidak melakukan kebohongan dalam hal sekecil apapun. 4). Mematuhi aturan yang telah dibuat oleh instansi. 5). Tidak membanding - bandingkan rekan kerja satu dengan yang lainnya.

Memiliki Keinginan Maju, Ialah membuka diri terhadap kritik dan saran, serta brusaha untuk selalu meningkatkan kualitas diri terutama yang berkaitan dalam hidup atau karir. Contohnya : 1). Tekun dalam melakukan segala hal. 2). Membuka diri terhadap kritik dan saran yang diberikan. 3). Selalu meningkatkan kualitas diri. 4). Tidak merendahkan hasil karya rekan kerja. 5). Memberikan kritik dan saran yang baik kepada rekan kerja ataupun dalam tim. Inisiatif, adalah kemampuan untuk dapat bertindak secara mandiri.

Contohnya : 1). kreatif sebagai seorang mahasiswa. 2). Memberikan ide baru dan menarik. 3). Saling memberikan motivasi sesama rekan kerja. 4). Selalu mempertimbangkan peluang yang ada. 5). Tidak menunda suatu ide jika telah mendapatkan ide baru. (Etos Kerja, Disiplin, Dan Komitmen Organisasi: 3). Contoh perilaku etos kerja: Dapat bertanggung jawab dalam pekerjaan karena diakhirat nanti akan dimintai pertanggung jawaban sesuai dengan apa yang sudah di kerjakan. Tidak meninggalkan sholat pada saat bekerja, karena sholat merupakan kewajiban setiap umat muslim.

Datang dengan tepat waktu ditempat kerja sesuai aturan yang berlaku, sehingga dapat melakukan pekerjaan dengan maksimal dan tidak menyianyiakan waktu. Bekerja dengan ikhlas dan penuh deangan kesabaran karena orang sabar disayang Allah SWT. Jujur dalam melakukan tindakan apapun di dalam pekerjaan jujur dalam menyusun laporan dan tidak ada unsur manipulasi. Mengawali setiap pekerjaan dengan membaca doa. Bersyukur dengan apa yang telah dimiliki kerana Allah SWT memberikan yang terbaik kepada umatnya. Mengakhiri setiap pekerjaan dengan mengucapkan syukur atau hamdallah. Rajin dan tekun dalam bekerja agar mendapatkan kepercayaan dari orang lain dan mampu menghargai pekerjaan kita. Teliti dalam melakukan pekerjaan agar tidak terjadi kesalahan. (Toto, 2002)

\section{Simpulan}

Berdasarkan hasil penelitian yang ditemukan pada bab sebelumnya 
maka dapat disimpulkan beberapa hal penting dalam penelitian ini yaitu :

1. Kepemimpinan berpengaruh positif dan signifikan terehadap Kinerja Karyawan Instalasi pada STEBIS Indo Global Mandiri Palembang artinya dengan kepimpinan yang baik maka pegawai akan meningkatkan kualitas dari tugas yang di emban dengan demikian kinerja akan meningkat.

2. Motivasi Kerja berpengaruh positif dan singnifikan terhadap Kinerja karyawan Instalasi pada STEBIS Indo Global Mandiri Palembang artinya Motivasi Kerja yang baik akan membuat karyawan akan meningkatkan kerjanya.

3. Etos Kerja berpengaruh positif dan signifikan terhadap Kinerja karyawan artinya Etos Kerja karyawan yang baik maka karyawan merasa nyaman dalam menjalankan aktifitas.

4. Secara Simultan kepimimpinan, Motivasi Kerja dan Etos Kerja berpengaruh postif dan signifikan terhadap kinerja karyawan artinya untuk dapat hasil yang dilakukan oleh karyawan lebih baik. Maka ketiga variabel tersebut dapat dijalankan secara bersamaan oleh Organisasi. Varisbel disiplin kerja merupakan variabel yang dominan. 
Etos Kerja Stebis Igm Di Sekolah Tinggi Ekonomi Dan Bisnis Syariah Indo Global Mandiri

Palembang

Ulpa Dwiyanti, Meriyati

\section{Daftar Pustaka}

Aravik, H. (2016). Ekonomi Islam: Konsep, Teori dan Aplikasi serta Pandangan Pemikiran Ekonomi Islam dari Abu Ubaid sampai al-Maududi. Empat Dua Intranspublishing.

Badan Penjaminan Mutu (BPM) Sekolah Tinggi Ekonomi dan Bisnis Syariah Indo Global Mandiri.

Etos Kerja, Disiplin, Dan Komitmen Organisasi Pengaruhnya Terhadap kinerja karyawan pada PT. HASJRAT ABADI Cabang MANADO. https://doi.org/10.35794/emba.p3i2.9284

Jurnal, Pengaruh Disiplin Kerja, Motivasi Kerja, Etos Kerja dan Lingkungan Kerja Terhadap Produktifitas Kerja Karyawan Bagian Produksi Di PT.Inko Java Semarang

Tasmara Toto. 2002, Membudayakan Etos Kerja Islami Jakarta: Gema Insani Pers. Pengaruh Etos Kerja Islami Dan Gaya Kepemimpinan Transformasional Terhadap Komitmen Organisasional Serta Implikasinya Pada Kinerja Pegawai Wilayahtul Hisbah Kota BANDA ACEH.

www.stebisigm.ac.id

Zamzam, H. F., \& Aravik, H. (2020). Etika Bisnis Islam Seni Berbisnis Keberkahan. Yogyakarta: Deepublish.

Zamzam, F., \& Aravik, H. (2016). Manajemen SDM Berbasis Syariah. Bogor: CV. RWTC Success. 